\title{
The Actuality of Agriculture Internet of Things for Applying and Popularizing in China
}

\author{
Ziyu Wu, Shijun Li *, Manhua Yu and Juxin Wu \\ Information \&Technology College, Jilin Agricultural University, Changchun, 130118, China.
}

Keywords: Internet of things, Agricultural IOT, System structure, Application and popularizing.

\begin{abstract}
With the development of global economic integration and information technology, the IOT technology has wide attention from all sectors of society, as the government also attaches great importance to the research and development of the Internet of things, and now its research and development has already penetrated into the social from all walks of life. At the same time, the application of the Internet of things in agricultural production is increasingly wide. It expounds the concept, system structure and characteristics of agricultural Internet of things. And it emphatically analyses the problems that are existent in the process of application and popularizing of the agricultural IOT.
\end{abstract}

\section{Introduction}

The IOT is the third wave of science and technology information industry in the world after the computer, the Internet and mobile communication network [1-4]. In recent years, as the development of intelligent agriculture[5,6], precision agriculture[7,8,9] and agricultural product quality safety traceability[10,11,12], the application of Internet technology, such as intelligence chip[13,14], RFID [15,16] and embedded system[17], gradually widened in the modern agriculture. Using the wireless sensor network can effectively reduce the human consumption and the impact on the farmland environment, and get accurate crop environment and crop information. Then farmers can monitor farmland information without leaving home through using various kinds of automatic intelligent and remote control production equipment [18,19]. It will implement the scientific monitoring and scientific planting, and promote modern agriculture to change its way of the development. The application of the agriculture IOT technology can better control the growth environment of crops, better adapt to the growth for the crops, achieve high and stable yield of crops, and improve crop yield and quality, the productivity of land and the ability of agriculture resist natural disasters[20]. The application and generalization of agricultural IOT, it is an important sign of agricultural modernization level. The rapid development of agricultural IOT will provide an international leading brand new platform for the development of Chinese agriculture, which will synchronize with the world, and also will certainly play a huge role to upgrade traditional industry [21].

\section{Concept of the agricultural IOT}

Agricultural Internet of things means that using a large number of sensor nodes constitute a monitoring network, through a variety of sensors to collect information, then help farmers find problems in time, and accurately determine the position of the problem. So people will gradually the center of agriculture, and the information and software will become the center of the agriculture production mode from isolated mechanical steering mode. A various kinds of automatic intelligent and remote control production equipment will be used. The agricultural IOT mainly relates to the field of environmental soil moisture monitoring, climate and weather monitoring, the automatic controlling of greenhouses, intelligent control system of the planting industry, husbandry and aquaculture automatic control system, food safety traceability, etc[22]. 


\section{Network Architecture}

From the point of view of network architecture, the agricultural IOT can be divided into perception layer, transport layer, data layer and service layer [23]. It implements the information flow, business flow, service flow and function flow, and they are coordinating and unifying, as described in detail below.

Perception layer. It acquires the agriculture information through different types of agricultural sensor products, which include the information of cropland, animal husbandry and aquaculture environment and the ontology of crops, soil and gas basic ingredients, animal physiology, plant diseases and insect pests in greenhouse environment.

Transport layer. By taking advantage of mainstream communication technologies such as China Telecom, CMCC and UNICOM, the transport layer passes the data quickly from perception layer, establishes the sensor communication interface of agricultural IOT, data description regulation, interoperability protocol for sensor nodes, etc. Then it can realize a variety of network adaptive to join seamlessly, and ensure that the data introduce into the agriculture IOT system successfully.

Data layer. Using cloud computing technology, the data layer is responsible for integrating the data and knowledge resources that are distribute in each unit, and to store, to manage, to excavate and to share vast amounts of data from perception layer. Because of different agricultural application and service theme, build the professional data warehouse, provide data and intellectual support for the whole project.

Service layer. Based on the data and knowledge from perception layer, the service layer will provide different management platform and service for agricultural production to government decision-making command center. In allusion to the user requirements from each link, such as production, processing, logistics, trade, consumption and so on, using mobile phones, TV, computer and other appropriate means establish accurate information push system to realize the personalized service of information and knowledge.

\section{Characteristics}

Firstly, the perception is the foundation of the agricultural IOT. Agricultural IOT is considered to have the subversive significance for traditional agricultural production, an important reason is that it has changed the fact, which agricultural personnel rely on limited agricultural knowledge to subjectively judge plants, soil and agricultural environment. Farmer all depend on a matter of experience and feel to watering, fertilizing and spray insecticide in traditional agriculture. However, with the passage of time, the experience may be omissions or fault, and relying on the feeling is also likely cause misjudgment. For the individual production, the loss caused by such errors will not be too big, but in the agricultural enterprise, the damage will greatly increase. So the advantage of the perception of agriculture is to highlight at this time [24].

Secondly, the chain is priority among priorities. After collecting the video, temperature, humidity, illumination and soil data through sensors, 3G communication technology or geographic information system, a series of system operation must be completed, for example precision fertilizer and irrigation. Then collect feedback information and make further judgment. Thus, the entire chain is to collect information, making decisions, implementation of operation and the follow-up feedback. If lack of any one link, that is difficult to call intelligent agriculture [25].

Thirdly, the "weapon" is the key. The "Weapon" is the products of agriculture IOT, which are the solutions of intelligent agricultural production.

\section{Problems in Application and Promotion}

Cultural level is low, the lack of information technology talents. The agricultural IOT needs the talents who must be familiar with knowledge both agricultural science and technology and the modern information technology. The related talents are very lack because of the insufficient 
attention for agricultural IOT and faulty training mechanism. Farmers will lack the ability of acquiring comprehensive information timely if their knowledge degree is low. Due to less chance to contact and learn the computer, their level of basic computer knowledge and operation is low really, and they hardly gain or release the agricultural information by the Internet. Different knowledge degree determines the different mode of agricultural production. The literate peasants can apply the greenhouse technology to grow vegetables, but many other peasants cannot. Almost all of peasants can't understand the enormous influence of agricultural IOT, so the application of IOT can't effectively popularization in agriculture.

Local government and farmers lack related awareness to build the agricultural IOT. Throughout the actual situation of agricultural production in our country, the current is a superposition period in which traditional agriculture, modern agriculture and information agriculture are concomitant, taking family as the unit and the decentralized agricultural production and operation mode still account for the principal part of agricultural production. Therefore, that is particularly important to develop agricultural socialized service system and to use the information technology to change the industry weakness of agricultural production in our country, which mainly expresses high decentralization, small scale and the low controllable degree and stability. However, local government, many cadres and farmers understand the agricultural IOT insufficiently, and their information conception is weak. They can't realize the necessity and significance of "Precision agriculture", "Network agriculture" and "Digital agriculture". These are seriously hindering the application of the agricultural IOT.

Still pilot stage. The development path of agricultural IOT should be that: Putting forward concept-Developing product-Demonstration experiment-Small scale application-Popularize widely-Everything connected. However, the development of agricultural IOT in our country is just at the period of demonstration experiment stage. At this stage, although the problems of related products and technology had basically solved, it still needs to work out effectively how to find the promotion shortcuts and how to reduce the application cost. The concept of agricultural IOT was not born at the locality, and local farmers have no this related demand. Therefore, if local farmers have no actual demand, the widespread use of agricultural IOT still faces enormous difficulty, although it's the development direction of agriculture in the future. For example Jiangsu province in which the development of IOT walks in the forefront in China, the area in a rapid economic growth is the aquaculture that has the actual demand firstly.

Development without a comprehensive. As currently envisioned, the application of agricultural IOT will eventually achieve from planting to selling and traces the whole industrial chain. It's mean, from farm to refrigerator and dining-table, to realize the connectivity and information sharing. However, nowadays the application of agricultural IOT mainly and only focus on the circulation of agricultural products, agricultural products quality tracking and other parts. The national pork quality safety traceability system and "agriculture super docking", which is generalized energetically by the government, are the most typical application example. This part of the application may be a breakthrough, meanwhile, but that also illustrates the long-range distance, which there is still a gap between realizing the real agricultural IOT.

Investment subject not clear. Investment is the initial motivation of each industry to starting, development and prosperity. But so far, we haven't seen an integrated investment pattern to be formed for the agricultural IOT. One of the main reason is that there is no a spontaneous, sustained and strong investment subject. The government's investment has certain driving effects, but it is easily to cause the waste of investment and a kind of bubble, if there is no deep observation and abundant experience for the bottom market. The investment construction of enterprise is also only some pilot, its demonstration effect is greater than the practical significance. As the main body of agricultural production, farmers are unable to bear the huge infrastructure construction of agricultural IOT, and they don't want to initiative to invest. 


\section{Summary}

From the current application case in our country, some preliminary applications have been carried out, and they have obtained the certain effect in some areas. However, the application of agricultural IOT is still in its infancy as a whole, and it is far from satisfy the actual demand of the development of modern agriculture, facility agriculture project and agricultural science and technology innovation project. That is mainly manifested in the following below. Firstly, the products related with IOT technology are still in the development stage, the stability and accuracy also need the further perfection. Secondly, the agricultural IOT is still on the stage of experiment and demonstration, and its application has yet to be further strengthened. Thirdly, people can't fully understand the necessity of agriculture IOT technology and the overall development direction of modern agriculture. Fourthly, lack of related application talents and experts, it is needed to train more information support teams.

\section{Acknowledgements}

This work was financially supported by JiLlin Agricultural University Colleg students' innovative entrepreneurial training program project:“ JiLin ShenNong Electronic Technology Company”and "The research and application of quality monitoring technology of deer products based on IOT (12SF31)".

\section{References}

[1] H.S.Ning, Q.Y. Xu, Liu: Acta Electronica Sinica, Vol.38 (2010) No.11, p.2590-2599. (In Chinese)

[2] H.B. Zhu, L.X. Yang and Q. Zhu: Journal of Nanjing University of Posts and Telecommunications (Natural Science), Vol. 31(2011) No.1, p.1-9. (In Chinese)

[3] Luigi Atzori, Antonio Iera, Giacomo Morabito: The Internet of Things, Vol.54 (2010) No.15, p.2787-2805

[4] Amardeo C. Sarma,João Girão: Identities in the Future Internet of Things, Vol.49 (2009) No.3, p.353-363

[5] Y.F. Chen, W.L. Gao and K. Qi: Journal of Agricultural Mechanization Research, (2014) No.8, p.1-5. (In Chinese)

[6] L. Peng: Journal of Changchun Normal University, Vol.33 (2014) No.1, p.59-60. (In Chinese)

[7] P.Z. Liu, X.W. Meng, P. Tian and Z.M. Deng: Computer Engineering \& Science, Vol.34 (2012) No.3, p.137-142. (In Chinese)

[8] D.J. He, C.H. Yang and Q. Yang: Transactions of the Chinese Society of Agricultural Engineering, Vol.28 (2012) No.7, p.78-85. (In Chinese)

[9] F.Y. Wang: Agricultural Science\&Technology and Equipment, Vol.8 (2012) No.218, p.71-72. (In Chinese)

[10] Q.L. Hu, A.M. Wang: Rural Economy, (2009) No.7, p.98-101. (In Chinese)

[11] J.B. Xu, H.Q. Deng and H.L. Zhou: Journal of Hunan Agricultural University (Social Sciences), Vol.9 (2008) No.2, p.24-28. (In Chinese)

[12] H.W. Bai, A.D. Sun, J. Chen and L.R. Sun: Jiangsu Journal of Agricultural Sciences, Vol.29 (2013) No.2, p.415-420.(In Chinese)

[13] L.C. Yin and L.B. Cui:Journal of Heilongjiang August First Land Reclamation University, Vol.29 (2011) No.5,p.104-107 (In Chinese) 
[14] D. Zhao, J.X. Xiao and Y. Liu:Transducer and Microsystem Technologies, Vol.33 (2014) No.9,p.4-7 (In Chinese)

[15] L.H. Wang,X.L. Wang and D. Chen:Journal of Wuhan Institute of Technology, Vol.35 (2013) No.1,p.65-70 (In Chinese)

[16] Y. Zhu, X.M. Zhang and N. Wang:Experimental Technology and Management, Vol.29 (2012) No.6,p.18-21 (In Chinese)

[17] W. Xiao: Journal of Communication University of China (Science and Technology), Vol.8 (2001) No.4, p.36-43 (In Chinese)

[18] Z.H. Qian and Y.J. Wang: Journal of Electronics \& Information Technology, Vol.35 (2013) No.1, p.215-227 (In Chinese)

[19] F. Gao, S.Q. Lu and Q.X. Xu:Journal of Zhejiang A\&F University,Vol. 27 (2010)NO.5, p.762769 (In Chinese)

[20] M.J. Yan, N. Xia and Z. Wan:Chinese Agricultural Science Bulletin, Vol.27 (2011) No.8, p.464-467(In Chinese)

[21] H.X. Zhu, F.L.Wang and R.X. Suo: Chinese Agricultural Science Bulletin, Vol.27 (2011) No.2, p.310-314(In Chinese)

[22] C.L. Zhang and W.Z. Shen:Journal of Northeast Agricultural University, Vol.42 (2011) No.5, p.1-5(In Chinese)

[23] Z.H. Qian and Y.J. Wang:Acta Electronica Sinica,Vol.40 (2012) No.5, p.1023-1029 (In Chinese)

[24] P.Z. Liu, X.W. Meng and P. Tian: Computer Engineering \& Science, Vol.34 (2012) No.3, p.137-141 (In Chinese)

[25] Y.D. Zhao, Y.F. Ma and Y.Z. Wang: Transactions of the Chinese Society for Agricultural Machinery, Vol.43 (2012) No.3, p. 46-51 (In Chinese) 